\title{
Contribution of Glycine Betaine and Proline to Water Deficit Tolerance in Pepper Plants
}

\author{
Camilo Escalante-Magaña, Luis F. Aguilar-Caamal, \\ Ileana Echevarría-Machado, Fátima Medina-Lara, \\ Lucila Sánchez Cach, and Manuel Martínez-Estévez ${ }^{1}$ \\ Unidad de Bioquímica y Biología Molecular de Plantas. Centro de \\ Investigación Científica de Yucatán, Calle 43 \#130, Col. Chuburná de \\ Hidalgo, 97200 Mérida, Yucatán, México
}

Additional index words. Water potential, relative water content, osmolytes, electrolyte leakage, drought stress, pepper

\begin{abstract}
Water stress is the main factor responsible for decreased productivity, which affects the growth and development of crops. Plants respond to stress by accumulating compatible solutes, which have a key role in osmotic adjustment, thereby resulting in osmoprotection of the plants. The loss of water can increase the concentration of compatible osmolytes and molecules that regulate the plant metabolism. These solutes can be metabolized as sugars (sucrose, fructose, trehalosa), amino acids (proline), an amphoteric quaternary amine (glycine betaine), and other low-molecular-weight metabolites. However, among all these compatible solutes, proline and glycine betaine occur the most. Proline is an amino acid that can accumulate in low concentrations under optimal conditions; however, stress conditions contribute to its increased content. Few data are available regarding the levels of endogenous glycine betaine on Solanaceae, which is considered a nonaccumulator under water deficit conditions. The objective of this research was to evaluate the role of compatible osmolytes, glycine betaine and proline, in Capsicum sp. plants under different water deficit conditions. In this study, the presence of endogenous levels of proline and glycine betaine in two species of pepper (Capsicum chinense var. Genesis and Rex and Capsicum annuum var. Padron) were found. The concentration levels of proline were 362, 292, and $246 \mu \mathrm{mol} \cdot \mathrm{g}^{-1} \mathrm{DW}$ for Genesis, Rex and Padron respectively, and irrigation conditions (rehydration) of proline levels increased to 381,395 , and $383 \mu \mathrm{mol} \cdot \mathrm{g}^{-1}$ DW at 21 days. However, glycine betaine levels were 30-70 $\mu \mathrm{mol} \cdot \mathrm{g}^{-1} \mathrm{DW}$. The relative water content, electrolyte leakage, and soil water potential were also analyzed; therefore, the information suggests that proline contributes better to tolerance to water deficit in the genus Capsicum after 14 days of water deficit treatment. It seems that the contribution of glycine betaine is less effective than that of proline; therefore, it does not have an important role in osmotic adjustment.
\end{abstract}

In recent years, it has been noted that extended droughts cause severe damage to several important crops in the main producing areas worldwide. Water shortages are responsible for the greatest crop losses, and they are expected to worsen (Comas et al., 2019). Water deficit is a critical abiotic factor that affects the growth and productivity of plants, especially in arid or semiarid regions of the planet (Bodner et al., 2015). This type of stress has become one of the main negative factors affecting agriculture because it limits plant growth, development, and productivity in many countries (Gosal et al., 2009; Xu et al., 2010; Zhu, 2002). The effects of water deficit are generally presented as inhibition of cell proliferation and expansion, reduction in leaf size, and reduction in stem length, resulting in an overall negative effect on the

Received for publication 13 Feb. 2019. Accepted for publication 27 Mar. 2019.

${ }^{1}$ Corresponding author. E-mail: luismanh@cicy. $\mathrm{mx}$. amount of aerial and radicular biomass (Harrison et al., 2013; Sekmen et al., 2014; Shanker et al., 2014; Zdravković et al., 2013). Under this kind of stress, plants commonly experience numerous metabolic, physiological, and biochemical changes (Hasanuzzaman et al., 2014). This abiotic stress, which arises from water deficiency, decreases the hydric potential of plants, which can induce reductions in $g_{\mathrm{S}}$ and photosynthesis, leading to decreased yield and productivity for most crops (Chen et al., 2012). Plants use water to maintain the flow of nutrients and their turgor; to avoid the loss of water due to evapotranspiration or any other process, plants have developed several alternative mechanisms to endure and tolerate this type of tension (Pimentel, 2004; Verlues et al., 2006). One mechanism that contributes to the toleration of water deficit is the activation of metabolic pathways that respond to the low water availability, such as osmotic adjustment (OA), which consists of reducing cellular damage by accumulating osmolytes or compatible solutes (Chaves et al., 2003). The aforementioned osmolytes are metabolites that accumulate inside the cell in high concentrations without causing metabolic harm such as polyols, which include sorbitol, mannitol, arabitol, and glycerol, and amino acids, which include proline (Pro), the quaternary amine glycine betaine (GB), dimethylsulfoniumpropionate, and the disaccharides sucrose and trehalose (Farooq et al., 2014; Jones et al., 1980; Yancey et al., 1982). Additionally, OA provides plants with a method of sustaining the water content of the cell, which is essential for cellular activity (Bartels and Sunkar, 2005; Javot et al., 2003).

The osmolytes Pro and GB have a fundamental role when higher plants are exposed to conditions such as osmotic, hydric, and oxidative stress because they help with water conservation and protect proteins and biological membranes (Ashraf and Foolad, 2007; Farooq et al., 2009a, 2009b). In many plant species, free Pro has an important role and accumulates most under stressful conditions (Bhaskara et al., 2015). The roles of Pro and its metabolism under stressful conditions in several species have received considerable attention, and it is currently generally accepted that Pro has a multifunctional role in the response of plants to stress (Kaur and Asthir, 2015; Mansour and Ali, 2017; Szabados and Savouré, 2010). In addition to its function as an osmolyte, Pro is a scavenger of reactive oxygen species (ROS) and can stabilize sub-cellular structures, thereby modulating the redox homeostasis of the cell and operating as a supply of energy and as a signal molecule interacting with other metabolic pathways during periods of stress (Kishor et al., 2005; Sharma et al., 2011; Szabados and Savouré, 2010; Verbruggen and Hermans, 2008). Therefore, it is very important to understand the regulation of Pro at a genetic level as well as its metabolism to produce plants that could sustain high biosynthesis of this amino acid to favor its accumulation and improve the resistance of the plant. Two distinct pathways, the glutamate (Glu) and the Ornitine (Orn) pathways, exist in higher plants for the biosynthesis of Pro (Hu et al., 1992; Roosens et al., 1998). Similarly, Pro degradation occurs in the mitochondria through the consecutive action of Pro dehydrogenase (PDH) and pyrroline5-carboxylate dehydrogenase $(\mathrm{P} 5 \mathrm{CDH})$ to produce $\mathrm{P} 5 \mathrm{C}$ and Glu, respectively (Per et al., 2017). An increase in Pro biosynthesis and a decrease in its degradation could imply that its accumulation under stressful conditions could lead to great benefits for plants (Chaitanya et al., 2009; Sharma et al., 2011).

GB is synthesized via two distinct pathways from two distinct substrates, choline and glycine (Ashraf and Foolad, 2007; Sakamoto and Murata, 2002). The osmolyte GB can accumulate in a several organisms such as plants, animals, bacteria, cyanobacteria, and algae (Rhodes and Hanson, 1993); its accumulation provides protection against several environmental factors such as drought, salinity, and cold (Ashraf and Foolad, 2007; Ashraf and Harris, 2004; Chen 
and Murata, 2008). GB is biosynthesized in plants when exposed to diverse environmental factors that cause stress, such as salinity. It has been observed that GB can be synthesized and accumulated; however, some species such as Oryza sativa, $A$. thaliana, and $N$. tabacum do not produce GB naturally (Rhodes and Hanson, 1993). Other studies suggested that osmotic stress-induced GB biosynthesis occurs via jasmonate signal transduction, which not only has a key role in osmotic stress resistance but also contributes to tolerance ( $\mathrm{Xu}$ et al., 2018). Furthermore, GB maintained a higher photosynthesis rate, thereby increasing the production and translocation of sucrose via phloem loading to enhance the plant response to low-phosphate stress ( $\mathrm{Li}$ et al., 2019). However, Wei et al. (2017) demonstrated that GB might regulate ion channel and transporters, resulting in high potassium and low sodium levels to enhance salt tolerance in transgenic plants under salt stress conditions.

The goal of this research was to determine which of the evaluated osmolytes could have a fundamental role in the water deficit tolerance of plants of the genus Capsicum (Capsicum chinense var. Rex and Genesis and Capsicum annuum var. Padron).

\section{Materials and Methods}

Plant material. The species Capsicum chinense (cultivars Rex and Genesis) and Capsicum annuum (cultivar Padron) were used in this study.

Seed disinfection. One hundred seeds of each of the three cultivars were disinfected. Briefly, the seeds were placed in Falcon tubes and washed with $50 \mathrm{~mL}$ of ethanol at $80 \%$ $(\mathrm{v} / \mathrm{v})$ under continuous agitation for $5 \mathrm{~min}$. Then, they were rinsed three times with sterile water, followed by a simple wash with $50 \mathrm{~mL}$ of commercial sodium hypochlorite (Cloralex $5 \% \mathrm{NaOCl})$ at $30 \%(\mathrm{v} / \mathrm{v})$ for $15 \mathrm{~min}$ and an additional five washes with sterile water. The seeds were subsequently maintained in sterile water for $48 \mathrm{~h}$ at $4{ }^{\circ} \mathrm{C}$ in darkness.

Seed germination. Disinfected seeds were planted in sowing trays with coconut fiber as the substrate. When germinated, the plantlets were watered with Hoagland solution at half its ionic strength once per week using $150 \mathrm{~mL}$ of solution per tray until the moment of transplantation. Hoagland solution (Hoagland and Arnon, 1950) contained the following: $1.2 \mathrm{~mm}$ $\mathrm{KNO}_{3}, 0.8 \mathrm{~mm} \mathrm{Ca}\left(\mathrm{NO}_{3}\right)_{2}, 0.2 \mathrm{~mm} \mathrm{KH}_{2} \mathrm{PO}_{4}$, $0.2 \mathrm{mM} \mathrm{MgSO}_{4}, 50 \mu \mathrm{M} \mathrm{CaCl}_{2}, 12.5 \mu \mathrm{M} \mathrm{H}_{3}$ $\mathrm{BO}_{3}, 1 \mu \mathrm{M} \mathrm{MnSO}{ }_{4}, 1 \mu \mathrm{M} \mathrm{ZnSO}{ }_{4}, 0.5 \mu \mathrm{M}$ $\mathrm{CuSO}_{4}, 0.1 \mu \mathrm{M}\left(\mathrm{NH}_{4}\right)_{6} \mathrm{Mo}_{7} \mathrm{O}_{24}$, and $10 \mu \mathrm{M}$ Fe-EDTA (pH 6.8; all the reagents used were from Sigma-Aldrich, Inc., St. Louis, MO).

Growth conditions. When the plants presented an average of six leaves, they were transplanted to black polyethylene bags (capacity of $6 \mathrm{~kg}$ ) with a height of $15 \mathrm{~cm}$ and containing $4 \mathrm{~kg}$ of a mixture of substrate, soil, and organic peat moss-based substrate with a proportion of $3: 1(\mathrm{v}: \mathrm{v})$. Then, they were taken to the greenhouse to standardize the size of the plants. Planting was performed during Jan. 2013; during this time, plants were maintained with $1 \mathrm{~L} \mathrm{H}_{2} \mathrm{O}$ until sufficient leaf tissue was collected.

Treatment of stress caused by water deficit. Twenty-five homogenous plants from each of the three pepper cultivars were used. Four plants were used for each of the five treatments, and five plants were used as controls. Experiments were performed under greenhouse conditions during the flowering stage. The treatment involved maintaining the plants without irrigation for $7,10,14,18$, and $21 \mathrm{~d}$; at the end of each treatment stage, the plants were watered at field capacity. Before applying the treatments, all pots were watered to saturation $\left(3 \mathrm{~L} \mathrm{H}_{2} \mathrm{O}\right)$, after which the plants were allowed to extract water for a period of $2 \mathrm{~d}$. At the end of the third day, the stress treatment had been established. One group of plants was watered on day 7 , the second group was watered on day 10, the third group was watered on day 14, the fourth group was watered on day 18 , and the last group was watered on day 21 . The control plants were maintained and hydrated with irrigation every third day $\left(1 \mathrm{~L} \mathrm{H}_{2} \mathrm{O}\right)$. Leaf tissue collection was performed after each stress treatment and at $24 \mathrm{~h}$ after irrigation (recovery stage). Twelve leaves were taken for each treatment and for each plant cultivar; these were weighed and divided into four parts to determine the relative water content (RWC), electrolyte leakage, and Pro and GB contents.

Measurement of soil water potential. Soil samples were collected from plants exposed to different treatments $(7,10,14,18$, and $21 \mathrm{~d})$ and from their respective control (wellhydrated plants). The samples were collected with a spatula at a distance of $10 \mathrm{~cm}$ from the stem and at a depth of $10 \mathrm{~cm}$, approximately two-thirds of the height of the bags, and were placed in trays that were then sealed with selfadhesive paper. These were subsequently stored in a thermos with ice for transportation. Measurements were performed using a WP4 Dewpoint PotentiaMeter (Decagon Devices, Inc.), which was previously calibrated with $0.5 \mathrm{M} \mathrm{KCl}$. The reading was adjusted to -2.19 $\mathrm{MPa}$, and distilled water $( \pm 0.1 \mathrm{MPa})$ was used to corroborate the calibration. A soil sample was collected for each replica of each treatment for each cultivar $(n=60)$; for the control, a sample was collected for each replica for each cultivar $(\mathrm{n}=15)$.

Determination of relative water content. To determine the RWC, the methodology reported by Smart and Bingham (1974) was used. Briefly, leaves were cut into discs with a diameter of $2.5 \mathrm{~mm}$ (using three discs per plant), and the fresh weight (FW) was registered. Subsequently, the discs were submerged in $20 \mathrm{~mL}$ of distilled $\mathrm{H}_{2} \mathrm{O}$ for $12 \mathrm{~h}$ to obtain the turgid weight (TW). Finally, the discs were dried in an oven at $40{ }^{\circ} \mathrm{C}$, and the dry weight (DW) was obtained. The RWC was calculated with the following formula:

$\mathrm{RWC}(\%)=(\mathrm{FW}-\mathrm{DW}) /(\mathrm{TW}-\mathrm{DW}) \times 100$

Measurement of electrolyte leakage. Permeability of the membrane was measured using electrolyte leakage and a modified method of Valentovič et al. (2006), which involved the following: with the aid of a hole punch, 12 leaf discs with a diameter of $2.5 \mathrm{~mm}$ were cut and transferred to Falcon tubes, to which $15 \mathrm{~mL}$ of deionized water was added; these were left to incubate for $24 \mathrm{~h}$ at $25^{\circ} \mathrm{C}$. Subsequently, the electrical conductivity (EC) was measured (L1) with a conductometer (Jenway 4010; Jenway Ltd., Dunmow, Essex, UK) and samples were placed in the autoclave at $120{ }^{\circ} \mathrm{C}$ for $20 \mathrm{~min}$, after which the samples were allowed to cool and the EC was measured (L2). Permeability of the membrane was calculated using the following formula:

\section{Electrolyte leakage $(\%)=(\mathrm{L} 1 / \mathrm{L} 2) \times 100$}

Quantification of proline content. Quantification of free Pro was performed using the method established by Bates et al. (1973) with modifications (all reagents were Sigma-Aldrich, Inc.). The ninhydrin acid reactive was prepared by placing $1.25 \mathrm{~g}$ of ninhydrin in $30 \mathrm{~mL}$ of glacial acetic acid and $20 \mathrm{~mL}$ of phosphoric acid $6 \mathrm{M}$ and agitating it until homogenized.

Approximately $0.01 \mathrm{~g}$ of finely ground leaf tissue (DW) was homogenized in $10 \mathrm{~mL} \mathrm{H}_{2} \mathrm{O}$ at the boiling temperature; after which, the residue was separated by centrifugation at $10,000 \mathrm{rpm}\left(9503 g_{\mathrm{n}}\right)$ for $15 \mathrm{~min}$ using a refrigerated centrifuge (Hettich Mikro 200R, Andreas Hettich GmbH \& Co. KG). Then, 2 $\mathrm{mL}$ of the sample was transferred to a test tube; after which, $2 \mathrm{~mL}$ of ninhydrin acid and $2 \mathrm{~mL}$ of glacial acetic acid were added and vigorously agitated.

The reaction mixture was heated in a water bath at $100{ }^{\circ} \mathrm{C}$ for $1 \mathrm{~h}(60 \mathrm{~min})$, during which the tubes remained covered with a glass sphere (marbles) to avoid evaporation of the mixture. When the incubation period ended, the reaction was halted by submerging the tubes in ice. The chromophore-Pro complex was extracted with $4 \mathrm{~mL}$ of toluene and vigorously agitated. The phase containing the chromophore was obtained, and its absorbance was determined in a spectrophotometer Thermo Spectronic Genesys 10 uv Scanning Spectro- photometer; Thermo Fisher Scientific, Madison, WI at a wavelength of $520 \mathrm{~nm}$. The absorbance values were compared with the standard curve values of Pro. A stock was prepared with a concentration of $1 \mathrm{mg} / \mathrm{mL}$. The concentrations used for the curve were $0-30 \mu \mathrm{g} / \mathrm{mL}$ of L-Pro, and calculations were performed using the following formula:

$$
\begin{aligned}
& \mu \text { moles proline } / \mathrm{g} \\
& =[(\mu \mathrm{g} \text { proline } / \mathrm{mL} \times \mathrm{mL} \text { toluene }) \\
& \quad / 115.5 \mu \mathrm{g} / \mu \mathrm{mol}] /[(\mathrm{g} \text { sample }) / 5]
\end{aligned}
$$

Determination of the glycine betaine content. The GB content was determined using the method of Grieve and Grattan (1983) with modifications (all reagents were from Sigma-Aldrich, Inc.). Finely ground dry material $(0.5 \mathrm{~g})$ was mixed with $20 \mathrm{~mL}$ of deionized water and maintained with mechanical agitation for $48 \mathrm{~h}$ at $25{ }^{\circ} \mathrm{C}$; subsequently, the mixture was centrifuged at 
10,000 rpm (9503 $g_{\mathrm{n}}$ ) for $10 \mathrm{~min}$ using a refrigerated centrifuge (Zentrifugen hettich, Mikro 200 R). The supernatant was collected and stored in the freezer until the analysis. Samples were thawed and diluted $(1: 1 \mathrm{v} / \mathrm{v})$ with $2 \mathrm{~N}$ of sulphuric acid $\left(\mathrm{H}_{2} \mathrm{SO}_{4}\right)$. An aliquot of $0.5 \mathrm{~mL}$ was collected and incubated for $1 \mathrm{~h}$ in ice; after which, $0.2 \mathrm{~mL}$ of cold potassium iodide-iodine $\left(\mathrm{KI}_{-} \mathrm{I}_{2}\right)$ was added and mixed gently. The samples were stored at 0 to $4{ }^{\circ} \mathrm{C}$ for $16 \mathrm{~h}$; after which, they were centrifuged at $10,000 g_{\mathrm{n}}$ for $15 \mathrm{~min}$ at $0{ }^{\circ} \mathrm{C}$. The supernatant was discarded while ensuring not to shake it; during this time, the samples were maintained in ice to allow separation of the periodide complexes from the acid medium. The periodide crystals that formed were dissolved in 9 $\mathrm{mL}$ of 1,2-dichloroethane, and the mixture was left to sit for $2 \mathrm{~h}$; after which, the absorbance (Thermo Spectronic Genesys 10 uv Scanning Spectrophotometer) was read at $365 \mathrm{~nm}$. For the standard GB curve, a stock comprising $1 \mathrm{mg} / \mathrm{mL}$ diluted in $1 \mathrm{~N} \mathrm{H}_{2} \mathrm{SO}_{4}$ was prepared; concentrations of $50-200 \mu \mathrm{g} /$ $\mathrm{mL}$ were used.

Statistical analysis. Data were analyzed using a one-way analysis of variance. Treatment averages were compared using Tukey's range test. We performed Pearson's correlations between the different pepper plants. All analyses were conducted using Sigma Stat Version 3.1 (Systat Software Inc., San Jose, CA).

\section{Results}

Determination of soil water potential. To identify the water stress conditions applied, the water potential of the soil samples taken from the cultivation area of the plants evaluated was determined. Figure 1 presents the water potentials of the samples collected. The results showed that as the water deficit increased due to the lack of water caused by evaporation or from the intake of plants, the water potential tended to decrease. This was similar to the outcomes of habanero pepper plants that were evaluated after being subjected to different stress levels that resulted in a loss of turgor in the leaves and other physiological effects, thereby provoking a response from the plant.

In soil that was completely hydrated, the water potential values reached $0 \mathrm{MPa}$ (data not shown); therefore, plants under these conditions were not considered during stress. However, in the case of the plants that received water every 7 and $10 \mathrm{~d}$, the soil values reached -0.102 and $-0.857 \mathrm{MPa}$. The plants subjected to $14 \mathrm{~d}$ of drought had a severe water deficit, with a value of -2.04 $\mathrm{MPa}$, which was similar to the plants subjected to $18 \mathrm{~d}$ of drought $(-5.829 \mathrm{MPa})$ and $21 \mathrm{~d}$ of drought $(-10.273 \mathrm{MPa})$. Therefore, we concluded that stress was present on day 14 of treatment. These results were in agreement with the outcomes of different irrigation times and water potential values, thus suggesting that 18 and $21 \mathrm{~d}$ of drought resulted in the most negative potential and could be considered the most severe treatments for the two Capsicum species evaluated.

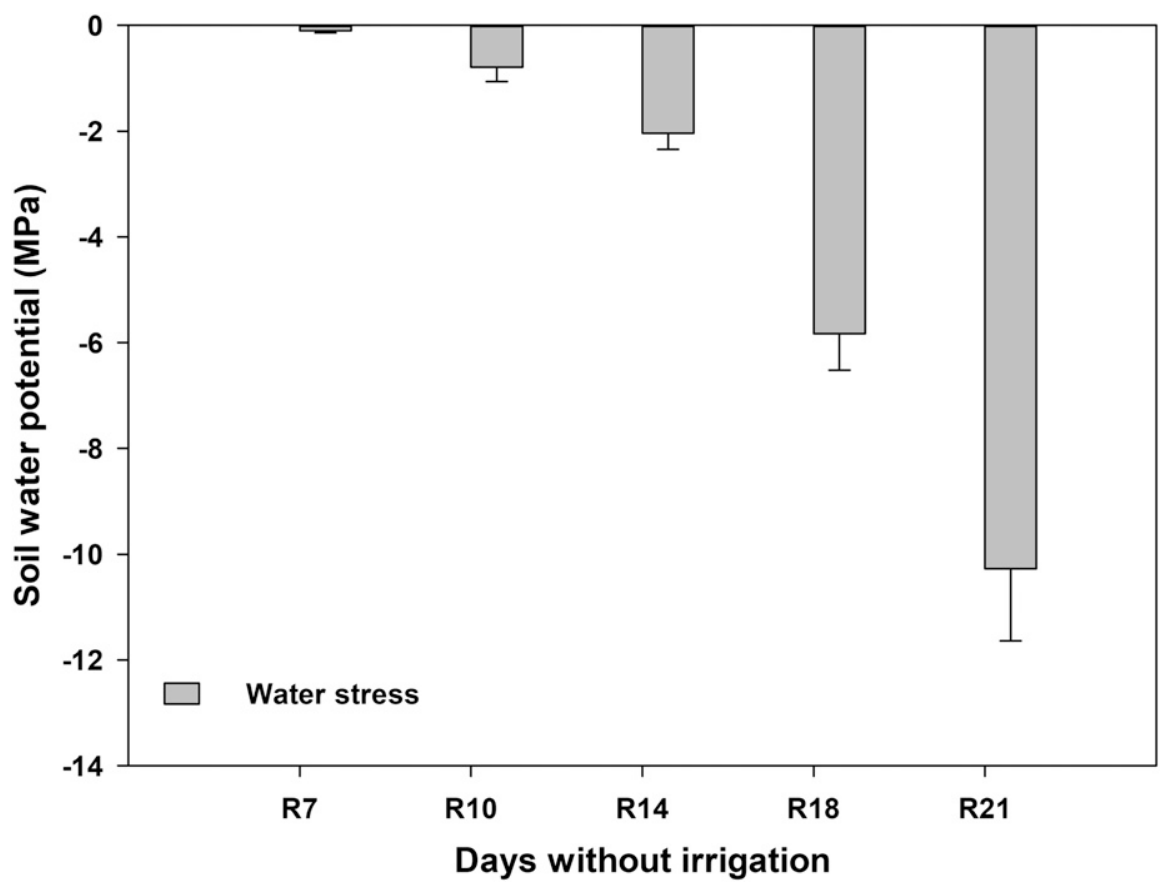

Fig. 1. Soil water potential of the plants subjected to different irrigation times.

Quantification of relative water content levels. RWC quantification of the leaves of these plants was performed to identify the status of the different plants evaluated regarding the water relationships. The results are shown in Fig. 2. After comparing the means, no significant difference was observed in the RWC among the $C$. chinense (Fig. 2A and B) and C. annuum (Fig. 2C) control plants; similarly, it was observed that these well-hydrated plants had an RWC more than $80 \%$. However, under water deficit conditions, the plants had significantly reduced RWC as the stress reached greater intensity. During the first $7 \mathrm{~d}$ of stress, the RWC levels of Genesis $(82.5 \%)$, Rex $(85 \%)$, and Padron (85\%) were determined (Fig. 2AC). At the end of the $21-\mathrm{d}$ treatment, the RWC values were $38.81 \%$ and $32.71 \%$ for the varieties Genesis and Rex, respectively. For the Padron cultivar of $C$. annuum, the RWC percentage on day 21 was $32.6 \%$. This indicated that the sensitivity to drought, at least in relation to the RWC, was dependent on the species and the genotype. As previously mentioned, when these plants are subjected to water stress, one parameter that allows us to identify their water status is the RWC, which is indicative of the quantity of water present in the plants. Additionally, another parameter of equal importance is the recovery capacity when subjected to hydration. This capacity of recovery allows us to predict when the plants will reach their permanent wilting point, which is the lowest water potential at which a plant can access water from soil; therefore, the recovery capacity of the pepper plants was evaluated. Furthermore, the plants under stress conditions were subjected to rehydration to field capacity; after $24 \mathrm{~h}$, the RWC was measured.
All plants subjected to the different irrigation schemes showed recovery in cell turgor, and the RWC returned rapidly to values similar to those of the control. The results of Genesis, Rex, and Padron are shown in Fig. 2D-F. These results demonstrated that the plants at $21 \mathrm{~d}$ had not reached the point of permanent wilting, which indicated that the two Capsicum species evaluated could have a level of tolerance to water deficit under the conditions used in this study.

Evaluation of membrane damage in plants subjected to water stress. The structural integrity of cell membranes is important for their survival under drought conditions or water deficit (Martínez et al., 2004). In addition, the maintenance of integrity and membrane stability are essential and recognized as important elements for the tolerance to drought (Bajji et al., 2002). The degree of stability of the cellular membrane is considered one of the principal indicators of when a plant is under water stress, and it has been used as a marker for tolerant or sensitive genotypes (Kocheva et al., 2004). Estimation of this stability according to electrolyte leakage has been used to differentiate tolerant and sensitive genotypes because this loss reflects the damage that occurs in membranes.

Figure 3 shows that the three control cultivars showed no significant difference in electrolyte leakage under conditions of daily watering.

Electrolyte leakage increased significantly during $7 \mathrm{~d}$ of treatment compared with the control group for the Genesis and Rex cultivars (Fig. 3A and B). The Padron cultivar did not present damages in the membranes at 7 and $10 \mathrm{~d}$ of water deficit treatment; however, on day 14, an increase 


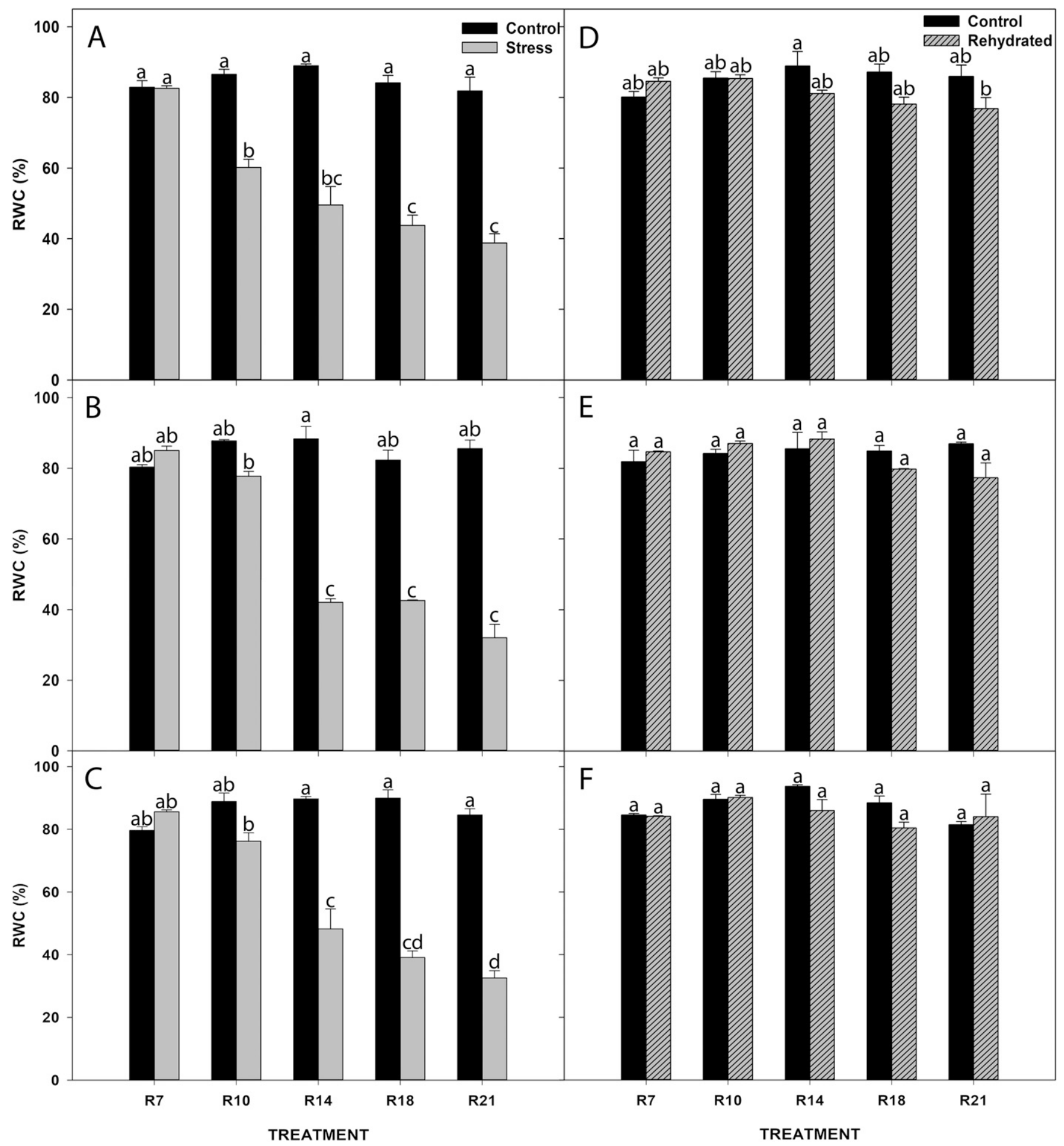

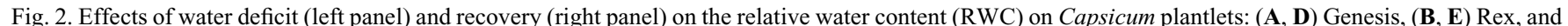
$(\mathbf{C}, \mathbf{F})$ Padron. The plants were subjected to different stress and irrigation regimens. Control plants were watered daily at field capacity. Means with the same letter indicate that they are not significantly different (Tukey $P \leq 0.05$ ).

of $63.7 \%$ in electrolyte leakage was observed (Fig. 3C). On day 21, the electrolyte leakage reached $93.2 \%$. For the Genesis cultivar, electrolyte leakage presented significant differences on day 7 of treatment, with a value of 45.6 that increased to $\approx 93.9 \%$ on day 21 (Fig. 3A). Similar behavior was observed for the Rex cultivar (Fig. 3B), for which electrolyte leakage reached $83.4 \%$ on day 14 of treatment and $93.9 \%$ on day 21 of treatment.

It was interesting to note that although electrolyte leakage was very high on day 21 without watering, the plants were capable of recovery when they were rehydrated. Moreover, a difference in the behavior of this parameter was observed in relation to the species. C. annuum seemed to have greater tolerance to the conditions of water deficit at the membrane level compared with that of $C$. chinense, for which electrolyte leakage was more severe during 14-d and 18-d treatments; the cultivars of both species reached the same percentage of electrolyte leakage on day 21 without watering. Considering the RWC (Fig. 2A-C) and the capacity of the plants to recover after rehydration (Fig. 2D-F), the 


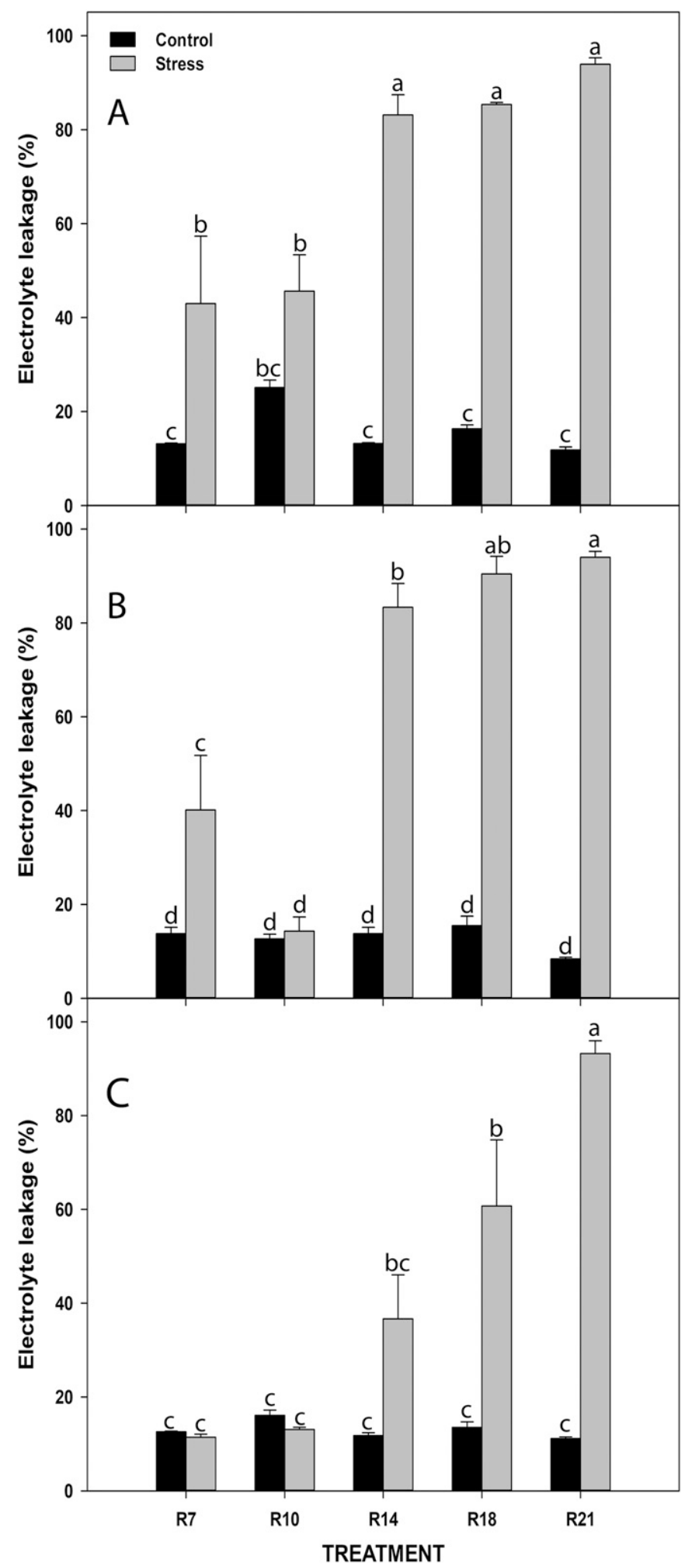

Fig. 3. Effects of water deficit on the percentage of electrolyte leakage in Capsicum plants subjected to different irrigation regimes: (A) Genesis, (B) Rex, and (C) Padron. Control plants were watered daily at field capacity. Means with the same letter indicate that they are not significantly different (Tukey $P \leq 0.05)$.

results clearly confirmed that the membranes recovered their capacity to maintain cellular turgor.

Quantification of the proline content in pepper plants subjected to water deficit. To determine if Pro has an important role in the tolerance to water deficit of Capsicum, quantification of the Pro content was subsequently performed to observe its possible participation in the OA of the three pepper cultivars subjected to different watering treatments.
The control plants of the three cultivars of peppers maintained almost constant Pro values between 13 and $31 \mu \mathrm{mol} \cdot \mathrm{g}^{-1} \mathrm{DW}$ (Fig. 4). Under stress conditions, Genesis exhibited a gradual increase in the concentrations of Pro (Fig. 4A); on day 7, the Pro level reached a value of $25.83 \mu \mathrm{mol} \cdot \mathrm{g}^{-1} \mathrm{DW}$, similar to the Pro concentration observed in plants that did not experience stress. The level of Pro had increased 14 times by day 14 of treatment, with a concentration of $234.77 \mu \mathrm{mol} \cdot \mathrm{g}^{-1} \mathrm{DW}$ (Fig. 4A). The maximum accumulation of Pro was observed on day 21 of treatment, with a value of 362.993 $\mu \mathrm{mol} \cdot \mathrm{g}^{-1} \mathrm{DW}$; this value represented an increase of 19 times compared with the control plants.

For the cultivar Rex (Fig. 4B), the Pro concentration on day 14 of treatment was $142.12 \mu \mathrm{mol} \cdot \mathrm{g}^{-1} \mathrm{DW}$, and the maximum level was obtained on day 21 , with a value of $292.32 \mu \mathrm{mol} \cdot \mathrm{g}^{-1} \mathrm{DW}$. This concentration was lower compared with that obtained for the Genesis cultivar.

Finally, for the Padron cultivar (Fig. 4C), the Pro level on day 14 increased up to 7.2 times compared with that of the control and up to 6.7 times compared with that on day 7 . The maximum concentration of Pro was found on day 18 of treatment, with a value of $304.32 \mu \mathrm{mol} \cdot \mathrm{g}^{-1} \mathrm{DW}$. This concentration may be the quantity required to maintain cellular turgor because on day 21 , the level decreased to a value of $246.25 \mu \mathrm{mol} \cdot \mathrm{g}^{-1} \mathrm{DW}$.

After irrigation for rehydration (Fig. 4DF), the Pro levels on day 14 exhibited a marked reduction and reached basal values. However, for the Genesis cultivar (Fig. 4D), the Pro level on day 18 was reduced to 256 $\mu \mathrm{mol} \cdot \mathrm{g}^{-1} \mathrm{DW}$. Subsequently, on day 21 , a contrasting effect was observed: the Pro level increased to $381.75 \mu \mathrm{mol} \cdot \mathrm{g}^{-1} \mathrm{DW}$. Finally, for the cultivars Rex and Padron (Fig. 4E and F), after rehydration, it was possible to observe behavior similar to that of Genesis until day 14; however, on day 18 , the levels were similar for both cultivars, with values between 150 and $200 \mu \mathrm{mol} \cdot \mathrm{g}^{-1} \mathrm{DW}$. On day 21 , the highest concentration of Pro was determined, and it was similar to the amount quantified for the Genesis cultivar, reaching $\approx 395 \mu \mathrm{mol} \cdot \mathrm{g}^{-1} \mathrm{DW}$.

Quantification of glycine betaine in pepper plants subjected to water deficit. GB is another osmolyte that has a role in OA and participates in the osmoprotection of plants under stress conditions. It has been reported to protect the photosynthetic machinery and also functions as a stabilizer of enzymes and a purifier of ROS (Anjum et al., 2012; Chaitanya et al., 2009; Rezaei et al., 2012).

During this study, quantification of this osmolyte was important to elucidate its contribution to the apparent tolerance to drought of the plants of the genus Capsicum. This was mainly because Solanaceas are considered to be non-natural accumulators of GB; in addition, few data are available regarding the endogenous contents of GB for this type of plant. The quantified results are shown in Fig. 5. On day 7 of treatment, the Genesis 


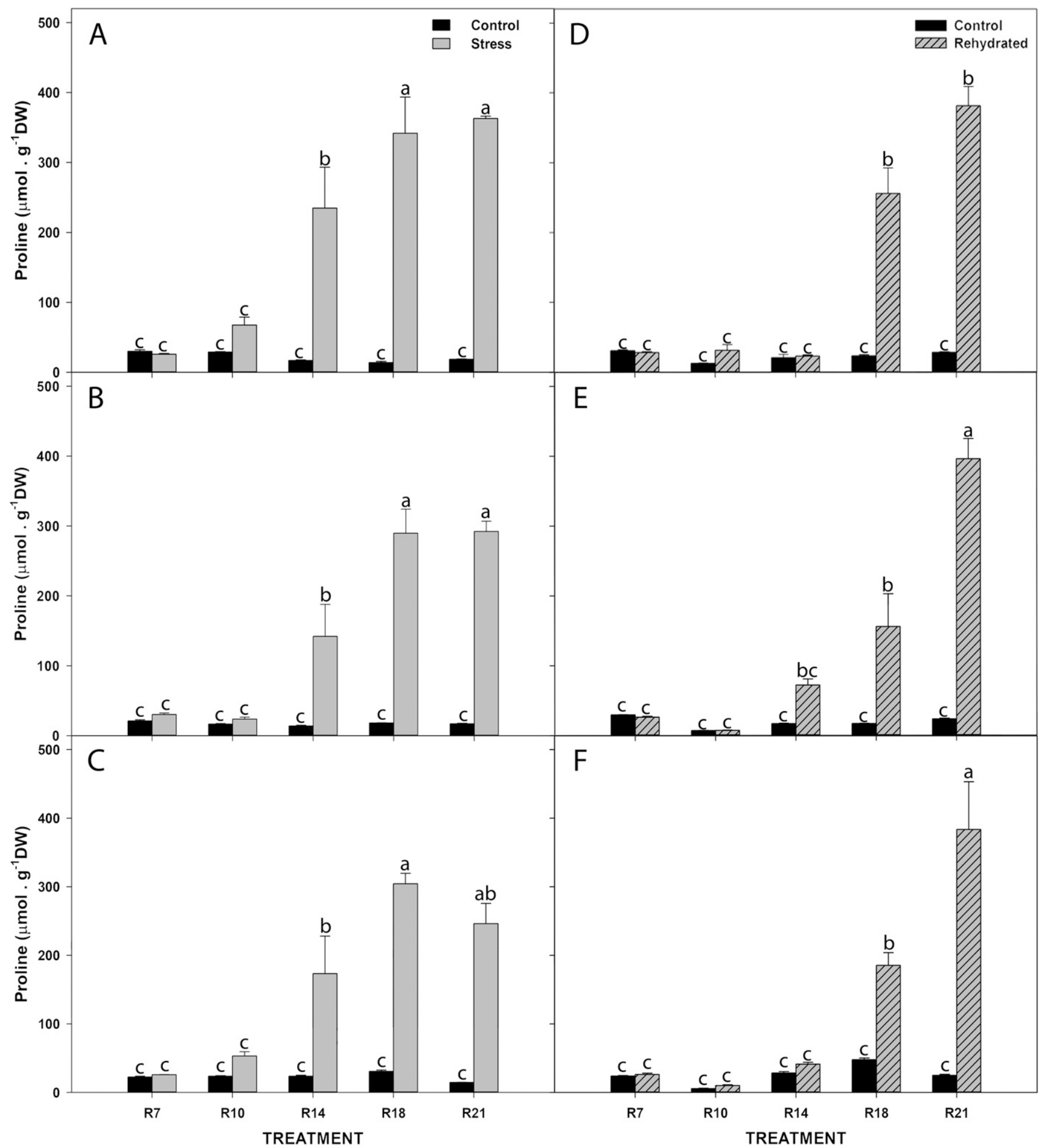

Fig. 4. Effects of water deficit (left panel) and recovery (right panel) on the content of proline in Capsicum plantlets: (A, D) Genesis, (B, E) Rex, (C, F) Padron. The plants were subjected to different stress and irrigation regimens. Control plants were irrigated daily at field capacity. Means with the same letter indicate that they are not significantly different (Tukey $P \leq 0.05$ ).

cultivar (Fig. 5A) showed a GB content of $26.94 \mu \mathrm{mol} \cdot \mathrm{g}^{-1} \mathrm{DW}$, which was increased on day 10 to $44.30 \mu \mathrm{mol} \cdot \mathrm{g}^{-1} \mathrm{DW}$. On day 21 , the GB level was $53.965 \mu \mathrm{mol} \cdot \mathrm{g}^{-1} \mathrm{DW}$, indicating that drier soils do not provoke significant changes in the concentration of this osmolyte. On day 7 , for the Rex cultivar (Fig. 5B), the GB level was $23.98 \mu \mathrm{mol} \cdot \mathrm{g}^{-1} \mathrm{DW}$; on day 10 , it was $56.28 \mu \mathrm{mol} \cdot \mathrm{g}^{-1} \mathrm{DW}$, almost 2.3-times higher compared with day 7 . This indicated that the mechanisms of GB biosynthesis are beginning to be affected by stress. By day 14 of treatment, the concentration of GB decreased almost 2.12 times compared with that on day 10 , reaching values similar to those found on day 7. After day 14, the GB values remained almost constant until day 21 , with a registered value of $39.18 \mu \mathrm{mol} \cdot \mathrm{g}^{-1} \mathrm{DW}$.

As was observed for Padron (Fig. 5 C), the results obtained on day 10 of treatment showed increased concentration of GB, with a value of $72.67 \mu \mathrm{mol} \cdot \mathrm{g}^{-1} \mathrm{DW}$. On day 21 , the level was $53.69 \mu \mathrm{mol} \cdot \mathrm{g}^{-1} \mathrm{DW}$; despite these rather notorious increases in GB, statistically 


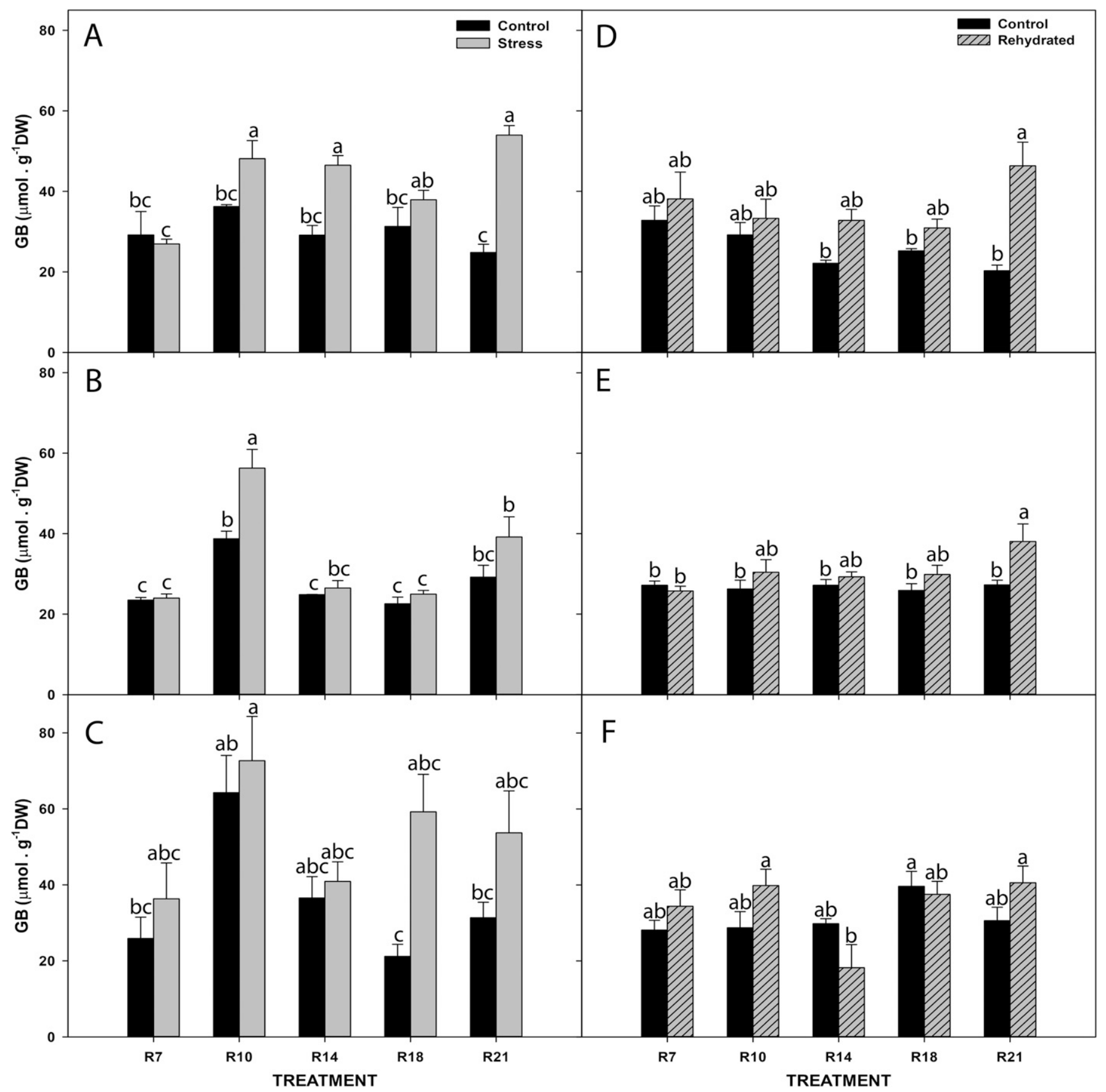

Fig. 5. Effects of water deficit (left panel) and recovery (right panel) on the glycine betaine content in Capsicum plantlets: (A, D) Genesis, (B, E) Rex, and (C, F) Padron. The plants were subjected to different stress and irrigation regimens and the control plants were irrigated daily at field capacity. Means with the same letter indicate that they are not significantly different (Tukey $P \leq 0.05$ ).

speaking, no significant differences were found for any of the stress treatments, which could indicate that GB accumulates as stress becomes more severe. This erratic behavior of the GB content suggested that this compound is not directly involved in the tolerance of these species to water deficit. An experiment consisting of recovery irrigation (rehydration) was proposed to determine if GB maintains its endogenous levels or reduces them when the Capsicum plants are rehydrated. The results are shown in Fig. 5D-F. These cultivars presented no differences in their GB contents; however, for Genesis
(Fig. 5D) control plants, the GB values ranging from $22-32 \mu \mathrm{mol} \cdot \mathrm{g}^{-1} \mathrm{DW}$ were registered, and the recently rehydrated plant values ranged from 30 to $46 \mu \mathrm{mol} \cdot \mathrm{g}^{-1} \mathrm{DW}$. In the case of the cultivar Rex (Fig. 5E), the GB concentration was ranged from 25 to 27 $\mu \mathrm{mol} \cdot \mathrm{g}^{-1}$ DW and 25-38 $\mu \mathrm{mol} \cdot \mathrm{g}^{-1}$ DW. Finally, for the cultivar Padron (Fig. 5F), the GB concentration ranged from 28 to 39 $\mu \mathrm{mol} \cdot \mathrm{g}^{-1} \mathrm{DW}$ and $18-40 \mu \mathrm{mol} \cdot \mathrm{g}^{-1} \mathrm{DW}$. This erratic behavior of the GB content could indicate that this compound is not directly involved in the tolerance of these species to water deficit. These cultivars presented no differences in their GB content when they were subjected to rehydration at field capacity. Their role of stress in GB accumulation is uncertain because, statistically, the levels of GB in plants, stressed or not, presented no difference. Moreover, during recovery stages, the GB levels are similar to those of plants under stress conditions. However, few data are available regarding the effects of GB on peppers, and most reports have focused mainly on the exogenous application of this compound.

Correlation between the relative water content and the proline and glycine betaine 

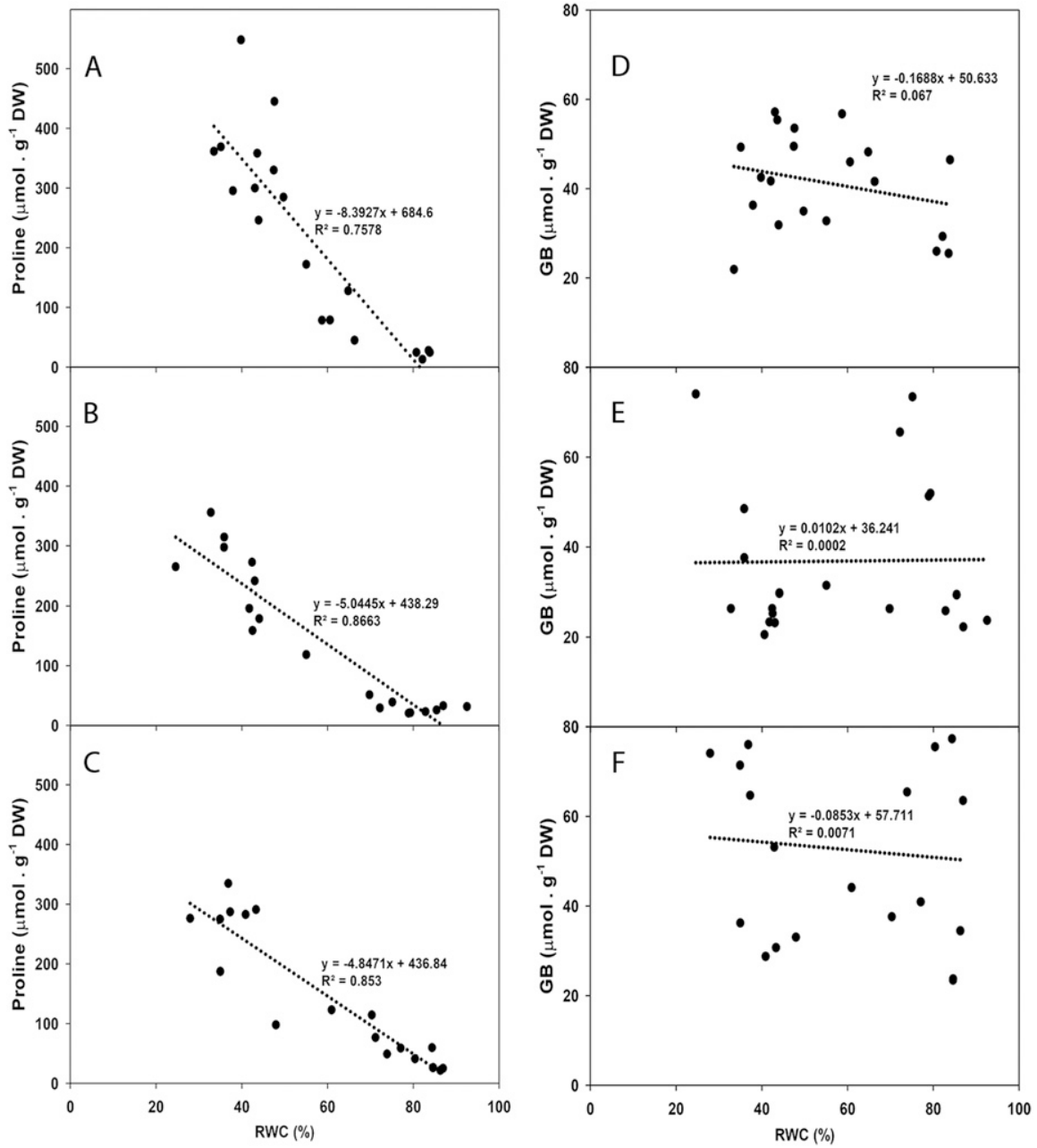

Fig. 6. Pearson's correlation between the relative water content and proline content (left panel) and between the relative water content and content of glycine betaine (right panel): $(\mathbf{A}, \mathbf{D})$ Genesis, $(\mathbf{B}, \mathbf{E})$ Rex, and (C, F) Padron. The plants were subjected to different stress regimens. Control plants were irrigated daily at field capacity.

contents in pepper plants subjected to water deficit. The RWC is a parameter that is considered to determine the levels of stress due to water deficit in plants. The correlation between RWC and Pro (Fig. 6A-C) and GB (Fig. 6D-F) concentrations are important to elucidate the function of these osmolytes to respond to different types of stress. It was possible to observe that Pro decreases as the percentage of RWC increases in all cultivars studied (Fig. 6A-C), indicating a close negative correlation between these variables $(P \leq 0.05)$. However, for GB (Fig. 6D-F), the correlation coefficients were very low, indicating very clearly that changes in the accumulation of GB had no relationship with the tolerance of pepper plants to water deficit.

\section{Discussion}

Due to the rapid changes in the environment on a global scale, the ability to cultivate and maintain a crop with good production is becoming increasingly difficult. Stress will inevitably lead to changes in morphology, physiology, and biochemistry, as well as to molecular changes resulting from the pro- ductivity of a crop (Boaretto et al., 2014; Mansori et al., 2015; Medici et al., 2014). Drought is one of the most predominant abiotic factors limiting the global productivity of agriculture (Gholipoor et al. 2012; Ihsan et al. 2016). It also affects growth and development due to the reduction of turgor in the leaves, resulting in reduced acquisition of nutrients from the soil by the plant (Luo et al. 2011).

Plants, as sessile organisms, possess strategies to mitigate the aforementioned problems and maintain the perpetuation of the species. One of these strategies is the synthesis of known substances such as compatible osmolytes, which include Pro and GB, among many others.

First, we can report that the plants of the three cultivars studied were subjected to water deficit from 7 to $21 \mathrm{~d}$ of treatment without irrigation, which allowed us to identify the stress conditions to which they were subjected. As a result of this study, it was possible to observe that RWC, electrolyte leakage, and water potential are modified as the water deficit becomes more severe. Regarding RWC, similar values were found by
Anjum et al. (2012), who evaluated different cultivars of C. annuum (cultivars Shansshu2001 and Nongchengjiao-2). They reported that after $12 \mathrm{~d}$ of treatment with severe water deficit, the plants presented a lower percentage of RWC, with the Shanshu-2001 cultivar presenting high values of RWC, and greater resistance to water deficit; they concluded that the cultivar Shanshu-2001 had greater tolerance to water deficit because it also continued accumulating soluble proteins, high Pro levels, greater turgor, and less damage in the membrane. Sahin et al. (2018), while evaluating cabbage plantlets (Brassica oleracea var. Capitata) using different irrigation regimens, were able to observe that the plants for which the treatment was most severe (close to $60 \%$ irrigation) presented less RWC. It was also possible to observe greater electrolyte leakage with the aforementioned treatment, and their results showed that in addition to electrolyte leakage, the plants presented higher concentrations of lipid peroxidation, which would indicate that with this treatment, the membranes would be damaged at membrane level, which could be harmful for the growth and development of cabbage. The RWC values for the three cultivars (Genesis, Rex, and Padron) were $82 \%$ to $86 \%$, and by the end of this experiment, values of $32 \%$ to $39 \%$ were reached. After analyzing the behavior of the different cultivars of the two species of the genus Capsicum, we determined that the Geneses cultivar was rapidly affected because it had reduced RWC after day 10 without irrigation. Plants subjected to slight stress, compared with Rex and Padron subjected to severe stress (Fig. 2), indicated the dependence of the genotype on this important parameter. When we studied types of abiotic stress, even within the same species, there were differences regarding tolerance. Results similar to ours were reported by $\mathrm{Ju}$ et al. (2018), who evaluated grape plants (Vitis vinifera $\mathrm{L}$.) with different water deficit times. The RWC showed that from day 15 of treatment, the plants exhibited lower RWC; however, this did not continue to diminish; at day 30 , they continued to present the same values as those on day 15 of treatment. This cultivar may have greater tolerance to water deficit because it loses water more quickly, but it is able to recover its turgor after rehydration in the same proportion as the other two cultivars studied. Therefore, we concluded that for these pepper species, the stress of $21 \mathrm{~d}$ without irrigation, despite having water potential more than $-10 \mathrm{MPa}$, is not stress that could indicate that the plants have reached their point of permanent wilting because when they are hydrated, they recover their turgor and continue their life cycle.

The stress from water deficit has an important role in the internal state of the plants, thereby causing damage in the cell membranes, which leads to rapid peroxidation of lipids, damage in the transportation systems, and other problems. Therefore, the permeability of the membranes of the three cultivars of pepper was evaluated. It was 
possible to observe that moderate stress, which appeared on day 14, was sufficient to initiate the damage of cell membranes, which would subsequently lead to the production of reactive oxygen species and rapid peroxidation of lipids in the membrane. Therefore, electrolyte leakage caused by damage in the membrane reflects the magnitude of the cell membrane lesion, which is why it has been used to differentiate between tolerant and susceptible genotypes (Rahman et al., 2004).

Although the measurements showed electrolyte leakage more than $80 \%$ in plants treated with $21 \mathrm{~d}$ of water deficit, they recovered satisfactorily when rehydration treatments were applied, which agreed with the outcomes reported by Mihailova et al. (2018) for Haberlea rhodopensis, a chlorophyllretaining resurrection plant. It is important to mention that the studies involving Capsicum plants examined the leaf, which is the organ that is first affected during stress due to water deficit.

Although all the cultivars presented moderate stress on day 14, Genesis (Fig. 3A) presented lower stability in its membranes from day 7 , which concurred with the RWC levels presented previously. Regarding the results presented for Rex (Fig. 3B) on day 7, these may be attributed to climatic changes. The presence of Pro (Fig. 4) increased from day 14 when the plant presented moderate stress and had water potential of $-2.04 \mathrm{MPa}$. The levels of imposed stress reached at day 21 were $\approx 240-263 \mu \mathrm{mol} \cdot \mathrm{g}^{-1} \mathrm{DW}$. However, when these plants were rehydrated, the levels on day 21 continued to increase. This increase in Pro levels during the rehydration stage is comparable with those reported by An et al. (2013), who found increases of $\approx 1.4$ $\mathrm{mg} \cdot \mathrm{g}^{-1} \mathrm{DW}$ and $2.0 \mathrm{mg} \cdot \mathrm{g}^{-1} \mathrm{DW}$ of Pro in hydrated plants after water stress for $24 \mathrm{~h}$ and $96 \mathrm{~h}(-1.0 \mathrm{MPa})$, respectively. The increase was also observed in different pepper cultivars from 6 to $24 \mathrm{~d}$ (Anjum et al., 2012) and in tomato cultivars (Moles et al., 2018). Similar studies performed for different cultivars of potato by Meise et al. (2018) report that when the plants were subjected to water stress for long periods of time (12 d), they had a greater accumulation of Pro and higher RWC. The authors concluded that there was a genetic variation in the cultivars regarding the treatments they evaluated, and that the roots may have systems that allow the transportation of Pro to be accumulated in leaves or roots. They also suggested that the Pro could be a target for the improvement of drought tolerance in potato.

Moreover, in grapes (Vitis vinifera L.), it has also been observed that after $10 \mathrm{~d}$ of treatment, the accumulation of Pro increased from $200 \mu \mathrm{g} \cdot \mathrm{g}^{-1} \mathrm{FW}$ to a maximum level of $500 \mu \mathrm{g} \cdot \mathrm{g}^{-1} \mathrm{FW}$ on day 20 (Ju et al., 2018); these results coincided with those of in our study. One possible explanation for this behavior could be a high accumulation of enzymes involved in the synthesis of Pro, such as P5CS (Szepesi and Szőllősi, 2018; Yoshiba et al., 1997). Therefore, it would be of significant interest to determine the activ- ity of the respective enzymes as well as the metabolism of the Pro in the presence of water deficit and during periods of recovery.

It has been reported that the exogenous application of GB provides tolerance to stress in accumulating and nonaccumulating species, although evidence suggested that the exogenous application of GB is not effective for all crops (Sulpice et al., 2002; Xing and Rajashekar, 1999). A toxic effect from the exogenous administration of GB has been observed in canola plants (Brassica napus L.), suggesting that it is not a compatible solute in all plants because one of the most important characteristics of a compatible solute is its accumulation in high concentrations without altering cell metabolism (Gibon and Larher, 1997).

Our results indicated that it was possible to observe that GB (Fig. 5) did not seem to be involved in $\mathrm{OA}$ or in osmoprotection. More importantly, it did not interfere with the endogenous levels of Pro. Previously, it was reported that exogenous administration of GB does not interfere with the metabolism of Pro (Korkmaz et al., 2012).

Based on the data regarding the correlation between Pro and RWC (Fig. 6A-C), we could clearly observe that the correlation was close to 1 for all the cultivars, with the cultivar Rex presenting a correlation value of -0.931 ; therefore, it can be suggested that Pro contributes to water relationships of the Capsicum plants evaluated. These data are comparable with those presented by Chowdhury et al. (2017), who found a strong relationship between Pro and the damage index for different cultivars of soya. The authors suggested that the synthesis of Pro and proteins played a fundamental role in the protection of cellular structures during stress caused by water deficit. It has been reported that the activation of this synthesis of both osmolytes and proteins allows plants to survive under conditions of stress by dehydration (Molaei et al., 2012). This beneficial protective function of Pro has also been observed in rice plants. Cha-Um and Kirdmanee (2010) observed that when rice plants were subjected to different concentrations of $\mathrm{NaCl}(50,100$, and $150 \mathrm{~mm})$ and to foliar spraying with $50 \mathrm{~mm}$ of $\mathrm{GB}$, the accumulation of Pro and efficient water use were favorably maintained. A close relationship between these two parameters was observed; therefore, the authors concluded that the foliar application of GB in optimal doses could be a favorable alternative used to improve the tolerance to salinity in rice plants. However, our results indicated that GB is not correlated with RWC (Fig. 6D-F) because its values were between -0.259 and 0.0127 . Therefore, based on other studies (Gibon and Larher, 1997; Korkmaz et al., 2012), we concluded that GB is not an osmolyte, as reported by Asma et al. (2006), who observed that the foliar application of GB to corn did not have the expected effect. Although it has been reported that GB acts as an osmoprotectant in some plant species, it is important to mention that these studies have only been performed in vitro (Saini et al., 2012).

In addition, few data regarding the effects of osmoprotection and endogenous presence of GB observed during the winter are available. Agboma et al. (1997) indicated that GB was exogenously applied to soya plants (Glycine $\max$ L.), thereby improving the effects of dehydration. Regarding pepper, which is considered a nonaccumulating species, in contrast to the report by Ponce et al. (1996), who did not find GB in pepper plants (Capsicum annum L.; Variedad Jupiter), our results indicated that it was possible to determine the endogenous presence of GB in Capsicum chinense (cultivars Genesis and Rex) and Capsicum annum L. (cultivar Padron) in the range of $20-80 \mu \mathrm{mol} \cdot \mathrm{g}^{-1} \mathrm{DW}$.

\section{Conclusion}

The results of this study suggested that in the presence of water deficit, pepper plants exhibit changes in the plasmatic membrane, RWC, and Pro content. In addition, regarding electrolyte leakage, the Genesis cultivar presented more sensibility and damage in the membrane, because it experienced more loss, whereas the cultivar Padron exhibited less damage. Similarly, regarding the RWC for three pepper cultivars, it was only possible to observe a significant reduction by applying stress from 14 to $21 \mathrm{~d}$. Of the three cultivars studied, Genesis had lower RWC on day 21 after the plants were rehydrated (recovery), and it was found that when all plants were subjected to recovery, the RWC values were similar to those of the control, suggesting that the treatment on day 21 does not involve stress that causes permanent wilting and death. The Genesis cultivar had the best response to water deficit, and it presented the highest Pro content compared with the Rex and Padron cultivars. We suggest that Pro is the osmolyte that could have an important role in the tolerance to water deficit; however, we also concluded that GB is not a key osmolyte when plants of the Capsicum genus are subjected to water deficit. Finally, in general, this study facilitated a better understanding of the behavior of the Capsicum genus (two species evaluated) in the presence of one type of abiotic stress and of the role of an amino acid (such as Pro) in tolerance. The results of this study will help future research studies that aim to identify the regulation of Pro metabolism and to ascertain the existence of osmolytes other than Pro that could participate in tolerance. Therefore, we suggest further investigations to respond to the new questions that will arise.

\section{Literature Cited}

Agboma, P. C., T. R. Sinclair, K. Jokinen, P. Peltonen-Sainio, and E. Pehu. 1997. An evaluation of the effect of exogenous glycinebetaine on the growth and yield of soybean: Timing of application, watering regimes and cultivars. Field Crops Res. 54(1):51-64.

An, Y., M. Zhang, G. Liu, R. Han, and Z. Liang. 2013. Proline accumulation in leaves of 
periploca sepium via both biosynthesis upregulation and transport during recovery from severe drought. PLoS One 8(7):e69942, doi: 10.1371/journal.pone.0069942.

Anjum, S.A., M. Farooq, X. Xie, X. Liu, and M.F. Ijaz. 2012. Antioxidant defense system and proline accumulation enables hot pepper to perform better under drought. Scientia Hort. 140:66-73.

Ashraf, M. and M.R. Foolad. 2007. Roles of glycine betaine and proline in improving plant abiotic resistance. Environ. Exp. Bot. 59:206-216.

Ashraf, M. and P.J.C. Harris. 2004. Potential biochemical indicators of salinity tolerance in plants. Plant Sci. 166:3-16.

Asma, M., M. Shahbaz, and N.A. Akram. 2006. Influence of exogenously applied glycine betaine on growth and gas exchange characteristics of maize (Zea mays L.). Pak. J. Agr. Sci. 43(1-2):36-41.

Bajji, M., J.-M. Kinet, and S. Lutts. 2002. The use of the electrolyte leakage method for assessing cell membrane stability as a water stress tolerance test in durum wheat. Plant Growth Regulat. 36(1):61-70.

Bartels, D. and R. Sunkar. 2005. Drought and salt tolerance in plants. CRC Crit. Rev. Plant Sci. 24(1):23-58.

Bates, L.S., R.P. Waldren, and I.D. Teare. 1973. Rapid determination of free proline for waterstress studies. Plant Soil 39(1):205-207.

Bhaskara, G.B., T.H. Yang, and P.E. Verslues. 2015. Dynamic proline metabolism: Importance and regulation in water limited environments. Front. Plant Sci. 6:484.

Boaretto, L.F., G. Carvalho, L. Borgo, S. Creste, M.G.A. Landell, P. Mazzafera, and R.A. Azevedo. 2014. Water stress reveals differential antioxidant responses of tolerant and nontolerant sugarcane genotypes. Plant Physiol. Biochem. 74:165-175.

Bodner, G., A. Nakhforoosh, and H.-P. Kaul. 2015. Management of crop water under drought: A review. Agron. Sustain. Dev. 35(2):401-442.

Chaitanya, K.V., G.K. Rasineni, and A.R. Reddy. 2009. Biochemical responses to drought stress in mulberry (Morus alba L.): Evaluation of proline, glycine betaine and abscisic acid accumulation in five cultivars. Acta Physiol. Plant. 31(3):437-443.

Cha-Um, S. and C. Kirdmanee. 2010. Effect of glycinebetaine on proline, water use, and photosynthetic efficiencies, and growth of rice seedlings under salt stress. Turk. J. Agr. For. 34(6):517-527.

Chaves, M.M., J.P. Maroco, and J.S. Pereira. 2003. Understanding plant responses to drought from genes to the whole plant. Funct. Plant Biol. 30:239-264.

Chen, T.H.H. and N. Murata. 2008. Glycine betaine: An effective protectant against abiotic stress in plants. Trends Plant Sci. 13:499-505.

Chen, X., D. Min, T.A. Yasir, and Y.-G. Hu. 2012. Evaluation of 14 morphological, yield-related and physiological traits as indicators of drought tolerance in Chinese winter bread wheat revealed by analysis of the membership function value of drought tolerance (MFVD). Field Crops Res. 137:195-201.

Chowdhury, J.A., M.A. Karim, Q.A. Khaliq, and A.U. Ahmed. 2017. Effect of drought stress on bio-chemical change and cell membrane stability of soybean genotypes. Bangladesh J. Agr. Res. 42(3):475-485.

Comas, L.H., T.J. Trout, K.C. DeJonge, H. Zhang, and S.M. Gleason. 2019. Water productivity under strategic growth stage-based deficit irrigation in maize. Agr. Water Mgt. 212:433-440.
Farooq, M., M. Hussain, and K.H.M. Siddique. 2014. Drought stress in wheat during flowering and grain-filling periods. CRC Crit. Rev. Plant Sci. 33(4):331-349.

Farooq, M., A. Wahid, O. Ito, D.J. Lee, and K.H.M. Siddique. 2009b. Advances in drought resistance of rice. Crit. Rev. Plant Sci. 28:199-217.

Farooq, M., A. Wahid, N. Kobayashi, D. Fujita, and S.M.A. Basra. 2009a. Plant drought stress: Effects, mechanisms and management. Agron. Sustain. Dev. 29:185-212.

Gholipoor, M., T.R. Sinclair, M.A.S. Raza, C. Löffler, M. Cooper, and C.D. Messina. 2012. Maize hybrid variability for transpiration decrease with progressive soil drying. J. Agron. Crop Sci. 199(1):23-29.

Gibon, Y. and F. Larher. 1997. Cycling assay for nicotinamide adenine dinucleotides: $\mathrm{NaCl}$ precipitation and ethanol solubilization of the reduced tetrazolium. Anal. Biochem. 251(2): 153-157.

Gosal, S.S., S.H. Wani, and M.S. Kang. 2009. Biotechnology and drought tolerance. J. Crop Improv. 23(1):19-54.

Grieve, C.M. and S.R. Grattan. 1983. Rapid assay for determination of water soluble quaternary ammonium compounds. Plant Soil 70(2):303-307.

Harrison, M.T., F. Tardieu, Z. Dong, C.D. Messina, and G.L. Hammer. 2013. Characterizing drought stress and trait influence on maize yield under current and future conditions. Glob. Change Biol. 20(3):867-878.

Hasanuzzaman, M., K. Nahar, S.S. Gill, and M. Fujita. 2014. Drought stress responses in plants, oxidative stress, and antioxidant defense, p. 209-237. In: N. Tuteja and S.S. Gill (eds.) Climate change and plant abiotic stress tolerance. Wiley-Blackwell, Germany.

Hoagland, D.R. and D.I. Arnon. 1950. The waterculture method for growing plants without soil. California Agricultural Experiment Station. Circular 347:1-2.

Hu, C.A., A.J. Delauney, and D.P. Verma. 1992. A bifunctional enzyme (delta 1-pyrroline-5carboxylate synthetase) catalyzes the first two steps in proline biosynthesis in plants. Proc. Natl. Acad. Sci. USA 89(19):9354-9358.

Ihsan, M.Z., F.S. El-Nakhlawy, S.M. Ismail, S. Fahad, and I. Daur. 2016. Wheat phenological development and growth studies as affected by drought and late season high temperature stress under arid environment. Front. Plant Sci. 7:795.

Javot, H., V. Lauvergeat, V. Santoni, F. MartinLaurent, J. Güçlü, J. Vinh, and C. Maurel. 2003. Role of a single aquaporin isoform in root water uptake. Plant Cell 15(2):509-522.

Jones, M.M., C.B. Osmond, and N.C. Turner. 1980. Accumulation of solutes in leaves of sorghum and sunflower in response to water deficits. Funct. Plant Biol. 7(2):193-205.

Ju, Y., X. Yue, X. Zhao, H. Zhao, and Y. Fang. 2018. Physiological, micro-morphological and metabolomic analysis of grapevine (Vitis vinifera L.) leaf of plants under water stress. Plant Physiol. Biochem. 130:501-510.

Kaur, G. and B. Asthir. 2015. Proline: A key player in plant abiotic stress tolerance. Biol. Plant. 59(4):609-619.

Kishor, P.B.K., S. Sangam, R.N. Amrutha, P.S. Laxmi, K.R. Naidu, K.R.S.S. Rao, and N. Sreenivasulu. 2005. Regulation of proline biosynthesis, degradation, uptake and transport in higher plants: Its implications in plant growth and abiotic stress tolerance. Curr. Sci. 88(3):424-438.

Kocheva, K., P. Lambrev, G. Georgiev, V. Goltsev, and M. Karabaliev. 2004. Evaluation of chlorophyll fluorescence and membrane injury in the leaves of barley cultivars under osmotic stress. Bioelectrochemistry 63(1):121-124.

Korkmaz, A., R. Şirikçi, F. Kocaçınar, Ö. Değer, and A.R. Demirkırıan. 2012. Alleviation of salt-induced adverse effects in pepper seedlings by seed application of glycinebetaine. Scientia Hort. 148:197-205.

Li, D., T. Zhang, M. Wang, Y. Liu, M. Brestic, T.H.H. Chen, and X. Yang. 2019. Genetic engineering of the biosynthesis of glycine betaine modulates phosphate homeostasis by regulating phosphate acquisition in tomato. Front. Plant Sci. 9:1-13.

Luo, Y., X. Zhao, R. Zhou, X. Zuo, J. Zhang, and Y. Li. 2011. Physiological acclimation of two psammophytes to repeated soil drought and rewatering. Acta Physiol. Plant. 33(1):79-91.

Mansori, M., H. Chernane, S. Latique, A. Benaliat, D. Hsissou, and M. E1 Kaoua. 2015. Seaweed extract effect on water deficit and antioxidative mechanisms in bean plants (Phaseolus vulgaris L.). J. Appl. Phycol. 27(4):1689-1698.

Mansour, M.M.F. and E.F. Ali. 2017. Evaluation of proline functions in saline conditions. Phytochemistry 140:52-68.

Martínez, J.-P., S. Lutts, A. Schanck, M. Bajji, and J.-M. Kinet. 2004. Is osmotic adjustment required for water stress resistance in the Mediterranean shrub Atriplex halimus L? J. Plant Physiol. 161(9):1041-1051.

Medici, L.O., F. Reinert, D.F. Carvalho, M. Kozak, and R.A. Azevedo. 2014. What about keeping plants well-watered? Environ. Exp. Bot. 99:38-42.

Meise, P., S. Seddig, R. Uptmoor, F. Ordon, and A. Schum. 2018. Impact of nitrogen supply on leaf water relations and physiological traits in a set of potato (Solanum tuberosum L.) cultivars under drought stress. J. Agron. Crop Sci. 204(4):359374.

Mihailova, G., K. Kocheva, V. Goltsev, H.M. Kalaji, and K. Georgieva. 2018. Application of a diffusion model to measure ion leakage of resurrection plant leaves undergoing desiccation. Plant Phyiol. Biochem. 125:185-192.

Molaei, P., A. Ebadi, A. Namvar, and T.K. Bejandi. 2012. Water relation, solute accumulation and cell membrane injury in sesame (Sesamum indicum L.) cultivars subjected to water stress. Ann. Biol. Res. 3(4):1833-1838.

Moles, T.M., L. Mariotti, L.F. De Pedro, L. Guglielminetti, P. Picciarelli, and A. Scartazza. 2018. Drought induced changes of leaf-to-root relationships in two tomato genotypes. Plant Physiol. Biochem. 128:24-31.

Per, T.S., N.A. Khan, P.S. Reddy, A. Masood, M. Hasanuzzaman, M. Iqbal, R. Khan, and N.A. Anjum. 2017. Approaches in modulating proline metabolism in plants for salt and drought stress tolerance: Phytohormones, mineral nutrients and transgenics. Plant Physiol. Biochem. 115:126-140.

Pimentel, C. 2004. A relação da planta com a água. RJ: Edur, Seropédica.

Ponce, V.M.T., S.G.S. Van, R. Ferreyra, A.J.M Peralta, A.S. Moyano, and R.P. Hinrichsen. 1996. Metabolic indicators of water stress as a possible criterion for the analysis of irrigation management: The case of sweet pepper (Capsicum annum L.). Agric. Téc. (Chillán) 56:57-63.

Rahman, H., S.A. Malik, and M. Saleem. 2004. Heat tolerance of upland cotton during the fruiting stage evaluated using cellular membrane thermostability. Field Crops Res. 85(2):149-158.

Rezaei, M.A., I. Jokar, M. Ghorbanli, B. Kaviani, and A. Kharabian-Masouleh. 2012. Morphophysiological improving effects of exogenous 
glycine betaine on tomato (Lycopersicum esculentum Mill.) cv. PS under drought stress conditions. Plant Omics 5(2):79-86.

Rhodes, D. and A.D. Hanson. 1993. Quaternary ammonium and tertiary sulfonium compounds in higher plants. Annu. Rev. Plant Physiol. Plant Mol. Biol. 44(1):357-384.

Roosens, N.H.C.J., T.T. Thu, H.M. Iskandar, and M. Jacobs. 1998. Isolation of the ornithine$\delta$-aminotransferase cDNA and effect of salt stress on its expression in Arabidopsis thaliana. Plant Physiol. 117(1):263-271.

Sahin, U., M. Ekinci, S. Ors, M. Turan, S. Yildiz, and E. Yildirim. 2018. Effects of individual and combined effects of salinity and drought on physiological, nutritional and biochemical properties of cabbage (Brassica oleracea var. capitata). Scientia Hort. 240:196-204.

Saini, U., D. Kaur, S. Chanda, A. Bhattacharya, and P.S. Ahuja. 2012. Application of betaine improves solution uptake and in vitro shoot multiplication in tea. Plant Growth Regulat. 67(1):65-72.

Sakamoto, A. and N. Murata. 2002. The role of glycine betaine in the protection of plants from stress: Clues from transgenic plants. Plant Cell Environ. 25:163-171.

Sekmen, A.H., R. Ozgur, B. Uzilday, and I. Turkan. 2014. Reactive oxygen species scavenging capacities of cotton (Gossypium hirsutum) cultivars under combined drought and heat induced oxidative stress. Environ. Exp. Bot. 99:141-149.

Shanker, A.K., M. Maheswari, S.K. Yadav, S. Desai, D. Bhanu, N.B. Attal, and B. Venkateswarlu. 2014. Drought stress responses in crops. Funct. Integr. Genomics 14(1):11-22.
Sharma, S., J.G. Villamor, and P.E. Verslues. 2011. Essential role of tissue-specific proline synthesis and catabolism in growth and redox balance at low water potential. Plant Physiol. 157(1):292304.

Smart, R.E. and G.E. Bingham. 1974. Rapid estimates of relative water content. Plant Physiol. 53(2):258-260.

Sulpice, R., Y. Gibon, A. Bouchereau, and F. Larher. 2002. Exogenously supplied glycine betaine in spinach and rapeseed leaf discs: Compatibility or non-compatibility? Plant Cell Environ. 21(12):1285-1292.

Szabados, L. and A. Savouré. 2010. Proline: A multifunctional amino acid. Trends Plant Sci. 15(2):89-97.

Szepesi, Á. and R. Szőllősi. 2018. Chapter 17 Mechanism of proline biosynthesis and role of proline metabolism enzymes under environmental stress in plants, p. 337-353. In: P. Ahmad, M.A. Ahanger, V.P. Singh, D.K Tripathi, P. Alam, and M.N. Alyemeni (eds.). Plant metabolites and regulation under environmental stress. Academic Press.

Valentovič, P., M. Luxová, L. Kolarovič, and O. Gašparíková. 2006. Effect of osmotic stress on compatible solutes content, membrane stability and water relations in two maize cultivars. Plant Soil Environ. 52(4):186-191.

Verbruggen, N. and C. Hermans. 2008. Proline accumulation in plants: A review. Amino Acids 35(4):753-759.

Verlues, P.E., M. Agarwal, S. Katiyar-Agarwal, J. Zhu, and J.K. Zhu. 2006. Methods and concepts in quantifying resistance to drought salt and freezing, abiotic stress that affect plant water status. Plant J. 45:523539.

Wei, D., W. Zhang, C. Wang, Q. Meng, G. Li, T.H. Chen, and X. Yang. 2017. Genetic engineering of the biosynthesis of glycinebetaine leads to alleviate salt-induced potassium efflux and enhances salt tolerance in tomato plants. Plant Sci. 257:74-83.

Xing, W. and C.B. Rajashekar. 1999. Alleviation of water stress in beans by exogenous glycine betaine. Plant Sci. 148(2):185-192.

Xu, Z., M. Sun, X. Jiang, H. Sun, X. Dang, H. Cong, and F. Qiao. 2018. Glycinebetaine biosynthesis in response to osmotic stress depends on jasmonate signaling in watermelon suspension cells. Front. Plant Sci. 9:1469.

Xu, Z., G. Zhou, and H. Shimizu. 2010. Plant responses to drought and rewatering. Plant Signal. Behav. 5(6):649-654.

Yancey, P.H., M.E. Clark, S.C. Hand, R.D. Bowlus, and G.N. Somero. 1982. Living with water stress: Evolution of osmolyte systems. Science 217(4566): 1214-1222.

Yoshiba, Y., T. Kiyosue, K. Nakashima, K. YamaguchiShinozaki, and K. Shinozaki. 1997. Regulation of levels of proline as an osmolyte in plants under water stress. Plant Cell Physiol. 38(10):10951102.

Zdravković, J., Z. Jovanović, M. Đorđević, Z. Girek, M. Zdravković, and R. Stikić. 2013. Application of stress susceptibility index for drought tolerance screening of tomato populations. Genetika 45(39):679-689.

Zhu, J.-K. 2002. Salt and drought stress signal transduction in plants. Annu. Rev. Plant Biol. 53(1):247-273. 